\title{
Sevoflurane suppresses proliferation by upregulating microRNA-203 in breast cancer cells
}

\author{
JIAYING LIU ${ }^{1}$, LONGQIU YANG ${ }^{2}$, XIA GUO $^{3}$, GUANGLI JIN ${ }^{4}$, QIMIN WANG $^{4}$, DONGDONG LV ${ }^{4}$, \\ JUNLI LIU ${ }^{1}$, QIU CHEN ${ }^{4}$, QIONG SONG ${ }^{4}$ and BAOLIN LI ${ }^{4}$ \\ ${ }^{1}$ Department of Anesthesiology, The Second Clinical College of Zhengzhou University, Zhengzhou, Henan 450003; \\ ${ }^{2}$ Department of Anesthesiology, Huangshi Central Hospital, Huangshi, Hubei 435000; \\ ${ }^{3}$ Department of Ophthalmology, Third People's Hospital of Jinan, Jinan, Shandong 250100; \\ ${ }^{4}$ Department of Anesthesiology, Zhengzhou Central Hospital Affiliated to \\ Zhengzhou University, Zhengzhou, Henan 450007, P.R. China
}

Received November 10, 2017; Accepted April 20, 2018

DOI: $10.3892 / \mathrm{mmr} .2018 .8949$

\begin{abstract}
Rapid proliferation is one of the critical characteristics of breast cancer. However, the underlying regulatory mechanism of breast cancer cell proliferation is largely unclear. The present study indicated that sevoflurane, one of inhalational anesthetics, could significantly suppress breast cancer cell proliferation by arresting cell cycle at G1 phase. Notably, the rescue experiment indicated that miR-203 was upregulated by sevoflurane and mediated the function of sevoflurane on suppressing the breast cancer cell proliferation. The present study indicated the function of the sevoflurane/miR-203 signaling pathway on regulating breast cancer cell proliferation. These results provide mechanistic insight into how the sevoflurane/miR-203 signaling pathway supresses proliferation of breast cancer cells, suggesting the sevoflurane/miR-203 pathway may be a potential target in the treatment of breast cancer.
\end{abstract}

\section{Introduction}

Breast cancer is one of the most common cancers in women worldwide. Rapid proliferation ensures the growth and the further invasion of breast cancer (1). Determination of the regulatory mechanism of breast cancer proliferation, eparticularly the cell cycle regulation, is important for diagnosis earlier and clinical therapy.

Correspondence to: Dr Qiong Song or Dr Baolin Li, Department of Anesthesiology, Zhengzhou Central Hospital Affiliated to Zhengzhou University, 195 Tongbai Road, Zhengzhou, Henan 450007, P.R. China

E-mail: doctorsq@126.com

E-mail: libaolin136@163.com

Key words: sevoflurane, breast cancer cell, proliferation, cell cycle, miR-203
Previous studies showed that sevoflurane, a common anesthetic, could repress the tumorigenesis of some types of cancers. For example, sevoflurane could inhibit the migration and invasion of glioma cells by upregulating the level of miR-637 (2). MMP-2 expression could be also repressed by sevoflurane to attenuate the migration of glioma cells (3). Sevoflurane inhibited hypoxia-induced growth and metastasis in lung cancer cells (4). Exposure to sevoflurane (1\%) for $6 \mathrm{~h}$ promoted the proliferation of human colon cancer (5). These studies showed the inhibitory function of sevoflurane on cancer initiation and development. However, whether or how sevoflurane regulates the breast cancer growth and the downstream regulatory signaling pathway remain largely unknown.

MicroRNAs (miRNAs) are small non-coding RNAs, which regulate gene expression by binding to the 3-untranslated regions (3'UTRs) of mRNAs (6). miRNAs participate in regulating many biological processes including the embryonic development, initiation of many diseases (6-10). Increasing studies have showed that miRNAs affect the proliferation, metastasis, invasion of cancer cells. Additionally, the expression level of miRNAs can also determine the pathogenesis classification, diagnosis and prognosis of cancer (11-13). Among these miRNAs, miR-29 family have been reported to be the tumor regulator and biomarker $(14,15)$. miR-106 promoted colorectal cancer cell migration and invasion by repressing the expression of DLC1 (16). Although more and more miRNAs were identified to be involved in cancer and other diseases, the particular roles of miRNA in different context of disease remain largely unknown. miR-203 has been also reported to be as the potential marker of the early detection of cervical cancer lymph node metastases. The low level of miR-203 was related to lymph node metastasis (17). A previous study showed that miR-203 repressed proliferation and induced apoptosis of colorectal cancer cells by post transcriptionally deregulating CPEB4 (18). However, prostate carcinoma patients with high miR-203 level showed lower average survival time than those with low miR-203 level (19). Although miR-203 showed different regulatory function in different cancers, miR-203 can be the critical regulator of some cancers and even the potential marker of diagnose. However, the function of miR-203 
on regulating the proliferation of breast cancer cells remains largely unknown.

In the present study we made the hypothesis that sevoflurane repressed the proliferation of breast cancer. In order to investigate the mechanism of proliferation regulation, we performed the cell cycle analysis and detected the miRNAs function and related regulatory signaling. This study may uncover the function of sevoflurane on regulating breast cancer cell proliferation and suggested the potential therapeutic target of miRNA for cancer prevention and treatment.

\section{Materials and methods}

Cell culture and sevoflurane treatment. Breast cancer cells were purchased from the Cell Bank Type Culture Collection of Chinese Academy of Sciences (CBTCCCAS; Shanghai, China) and cultured in RPMI-1640 medium (Gibco; Thermo Fisher Scientific, Inc., Waltham, MA, USA) with fetal bovine serum (10\%) (Gibco; Thermo Fisher Scientific, Inc.) at $37^{\circ} \mathrm{C}$, in a humidified atmosphere containing $\mathrm{CO}_{2}(5 \%)$. The culture medium was added $100 \mathrm{U} / \mathrm{ml}$ of penicillin sodium (Invitrogen; Thermo Fisher Scientific, Inc., Waltham, MA, USA), and $100 \mathrm{mg} / \mathrm{ml}$ of streptomycin sulfate (Invitrogen; Thermo Fisher Scientific, Inc.). Cells were exposed to $2 \%$ sevoflurane for $6 \mathrm{~h}$ as previously described $(5,20) .2 \%$ sevoflurane is clinically relevant and regulates the proliferation of human hepatocellular carcinoma cells (21). $\mathrm{CO}_{2}, \mathrm{O}_{2}$ and sevoflurane concentration was monitored by A Drager Vamos gas analyzer (Drager, Lübeck, Germany). The cells used for each experiments were culture in the 6 wells dish and seeded at the concentration of $1 \times 10^{5} /$ well.

Overexpression and inhibition of miRNA. Pre-miR-203, miRNA-203 inhibitor and the control miRNA were synthetic nucleic acids (Biotend, Shanghai, China). Pre-miRNAs can be processed by enzymes to become mature miRNAs. miRNA inhibitor has reverse complementary sequence of the miRNA. Lipofectamine 2000 (Invitrogen; Thermo Fisher Scientific, Inc.) was used for transfection of the pre-miRNA or inhibitor into cells which grown to approximately confluence (80\%).

MTS proliferation assay. Proliferation was detected by CellTiter $96^{\circledR}$. A Queous One Solution Cell Proliferation Assay kit (Promega Corporation, Madison, WI, USA) was used to perform the 3-(4,5-dimethylthiazol-2-yl)5-(3-carboxymethoxyphenyl)-2-(4-sul-fophenyl)-2H-tetrazolium (MTS) assay by following the instruction. The record absorbance at $490 \mathrm{~nm}$ was detected by microplate reader. We performed the detection every 24 h during 3 days.

Bromodeoxyuridine (BrdU) incorporation assay. Cells were seeded in 96-wells $\left(2 \times 10^{3}\right.$ cells/well) in the culture medium with BrdU incubation. After $2 \mathrm{~h}$, phosphate-buffered saline (PBS) solution with paraformaldehyde (PFA) (4\%) was used to fix cells for $20 \mathrm{~min}$. Cells were washed by PBS and treated by DNase for $20 \mathrm{~min}$ at room temperature. Then, BrdU primary antibody (Abcam, Cambridge, MA, USA) was added and incubated at $4^{\circ} \mathrm{C}$ for $12 \mathrm{~h}$. After washing by PBS, cells were incubated with secondary antibody at room temperature for $60 \mathrm{~min}$. Cell nucleus were dyed by 4',6-diamidino-2-phenylindole (DAPI)
(Sigma-Aldrich; Merck KGaA). BrdU-positive cells were counted by microscope.

Reverse transcription-quantitative polymerase chain reaction (RT-qPCR). RNAiso (Takara Bio, Inc., Otsu, Japan) was used for isolating total RNA. For reverse-transcription of miRNA, miRNA specific stem-loop reverse-transcription primer (Ribobio, China) was used. The amount of gene expression (2- $\Delta \Delta \mathrm{Ct}$ ) was normalized tothe endogenous nuclear RNA U6 using miRNA-specific primers (RiboBio Co., Ltd., Guangzhou, China). For mRNA RT-qPCR, cDNA was reverse-transcribed from mRNA by M-MLV Reverse Transcriptase (Takara) using random primers and oligo (dT) primers. The quantification of level of target gene expression $\left(2^{-\Delta \Delta \mathrm{Ct}}\right)$ was normalized to the endogenous GAPDH mRNA $(7,22)$. The reaction conditions of PCR were according to the SYBR-Green qPCR Mix instruction (Bio-Rad Laboratories, Inc., Hercules, CA, USA). The primers sequences are as follows: Cyclin E1, PF, 5'-ACT CAACGTGCAAGCCTCG-3', PR, 5'-GCTCAAGAAAGT GCTGATCCC-3'; Cyclin D1, PF, 5'-CAATGACCCCGC ACGATTTC-3', PR, 5'-CATGGAGGGCGGATTGGAA-3'; P21, PF, 5'-TGTCCGTCAGAACCCATGC-3', PR, 5'-AAA GTCGAAGTTCCATCGCTC-3'; P27, PF, 5'-TAATTGGGG CTCCGGCTAACT-3', PR, 5'-TGCAGGTCGCTTCCTTAT TCC-3'; RB1, PF, 5'-TTGGATCACAGCGATACAAACTT-3', PR, 5'-AGCGCACGCCAATAAAGACAT-3'. The primers of miRNA RT-qPCR were purchased from the RiboBio Co., Ltd. The thermocycling condition for mRNA is as follows: For mRNA: $95^{\circ} \mathrm{C}$ for $30 \mathrm{sec}$ followed by 40 cycles of $95^{\circ} \mathrm{C}$ for $10 \mathrm{sec}, 60^{\circ} \mathrm{C}$ for $30 \mathrm{sec}, 70^{\circ} \mathrm{C}$ for $30 \mathrm{sec}$. For miRNA: $95^{\circ} \mathrm{C}$ for $30 \mathrm{sec}$ followed by $40 \mathrm{cycles}$ of $95^{\circ} \mathrm{C}$ for $5 \mathrm{sec}, 60^{\circ} \mathrm{C}$ for $20 \mathrm{sec}$, $70^{\circ} \mathrm{C}$ for $10 \mathrm{sec}$.

Western blot analysis. Proteins from MDA-MB-231 cells were lysed and then transfered onto PVDF membranes (What man, England). Then incubated the membranes with the primary antibodies diluted by TBST (Beyotime, China) at room temperature for $2 \mathrm{~h}$. The primary antibodies are as follows: Anti-GAPDH (ab9485, Abcam, USA), anti-cyclin E (ab135380, Abcam), anti-cyclin D (ab134175, Abcam), anti-P21 (ab109520, Abcam), anti-P27 (ab32034, Abcam), anti-Rb1 (ab181616, Abcam). Then incubated the membranes with secondary antibodies diluted by TBST (Beyotime) according to the primary antibodies at room temperature for $1 \mathrm{~h}$. Protein signals were detected using enhanced chemiluminescence (ECL).

Statistical analyses. For statistical analyses, student's t-test or one way ANOVA with Boferroni's correction was used. The values were showed as the mean $\pm \mathrm{SD}$. $\mathrm{P}<0.05$ was defined as statistically significant.

\section{Results}

Sevoflurane inhibits the proliferation of breast cancer cells. In order to determine the function of sevoflurane on breast cancer cells proliferation, MDA-MB-231 or MCF-7 cells were treated with sevoflurane $(2 \%)$ for $6 \mathrm{~h}$ and cultured for another 24, 48 and $72 \mathrm{~h}$ without sevoflurane. The proliferation capacity was detected by MTS assay. The results showed that sevoflurane decreased proliferation of MDA-MB-231 
A

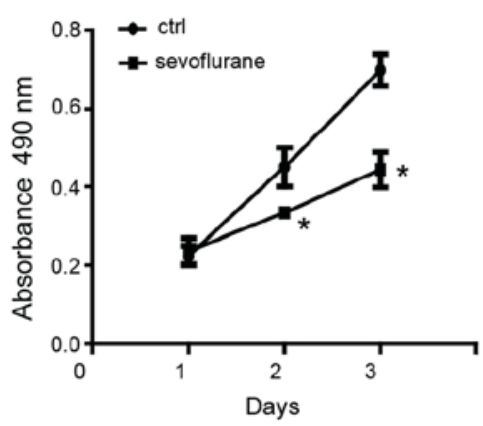

C

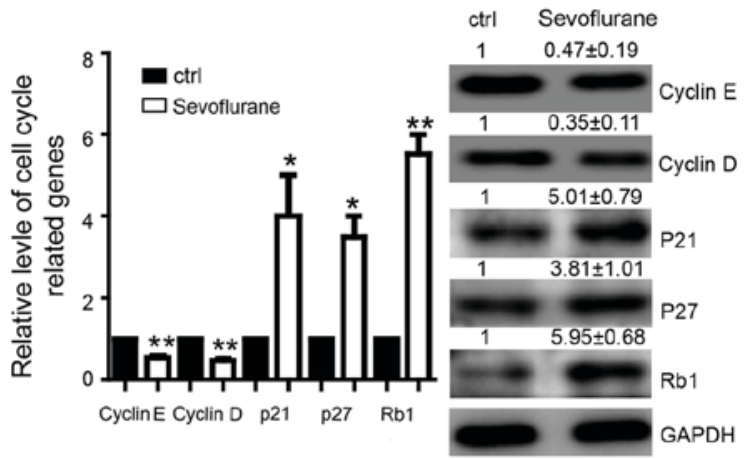

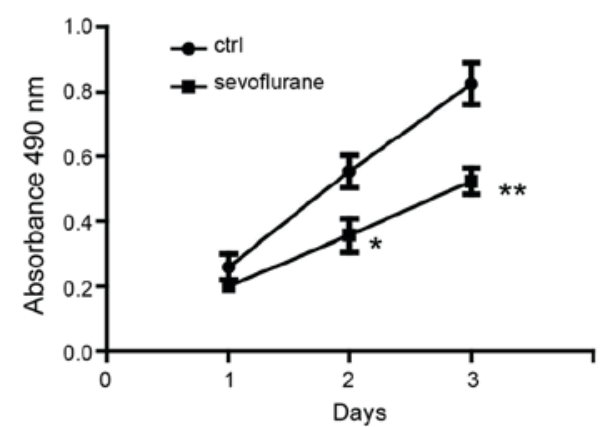

D
B

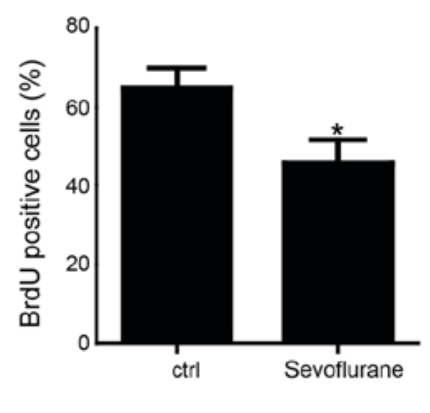

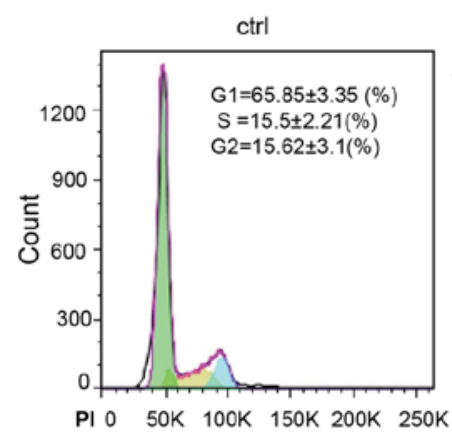

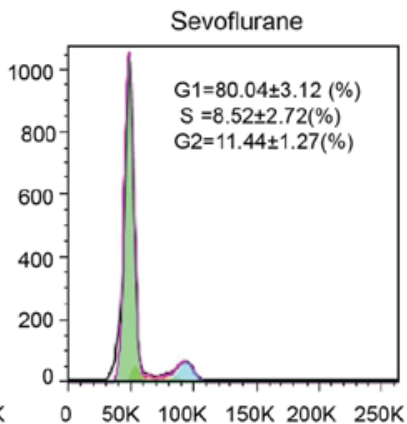

Figure 1. Sevoflurane inhibited the proliferation of MDA-MB-231 cells. (A) MTS assay showed the repression of proliferation of MDA-MB-231 (left panel) and MCF-7 (right panel) cells treated by sevoflurane. Ctrl means the control group without sevoflurane treatment. (B) BrdU incorporation assay showed the repression of proliferation capacity of MDA-MB-231 cells treated with sevoflurane. (C) Expression level of cell cycle-related genes (cyclin E, cyclin D, P21, P27, Rb1) was detected by RT-qPCR. (D) Flow cytometry assay showed sevoflurane led to the arrest of cell cycle at G1 phase detected in MDA-MB-231 cells. Data are shown as means $\pm \mathrm{SD}(\mathrm{n}=3-8) .{ }^{*} \mathrm{P}<0.05,{ }^{* *} \mathrm{P}<0.01$ vs. the corresponding control.

or MCF-7 cells (Fig. 1A). The BrdU incorporation assay in MDA-MB-231 cells was performed and cells treated with sevoflurane $(2 \%)$ for $6 \mathrm{~h}$ and then cultured for another $24 \mathrm{~h}$ without sevoflurane were found showing decreased proliferation capacity (Fig. 1B). We further detected the cycle-related genes in MDA-MB-231 cells and found that the level of cyclin $\mathrm{D}$, cyclin $\mathrm{E}$, which have been reported to be the critical regulatory genes of G1 phase, were significantly downregulated. In contrary, the expression of Rb1, P21, P27, the cell cycle-inhibiting genes, were upregulated compared with control group on both mRNA and protein levels (Fig. 1C). Flow cytometry assay showed that proportion of cells at G1 phase was increased and cells at the S, G2/M phase was decreased after treating by sevoflurane in MDA-MB-231 cells (Fig. 1D).

miR-203 is upregulated by sevoflurane and repressed the proliferation of breast cancer cells. Using RT-qPCR, we detected that miR-203 could be upregulated in MDA-MB-231 cells treated with sevoflurane (Fig. 2A). To determine the effect of miR-203, we transfected the pre-miR-203 into MDA-MB-231 cells and found that miR-203 significantly repressed the proliferation in both MDA-MB-231 and MCF-7 cells (Fig. 2B and C). In contrast, transfection of the miR-203 inhibitor whose efficiency was determined by detecting the target gene SNAI2 level (23) promoted the proliferation of MDA-MB-231 and MCF-7 cells detected by MTS assay (Fig. 2B). BrdU incorporation assay in MDA-MB-231 cells also indicated the similar results (Fig. 2C). Expression level of cyclin D, cyclin E was downregulated in cells transfected with pre-miR203 (Fig. 2D) and upregulated in the MDA-MB-231 cells transfected with miR-203 inhibitor (Fig. 2E). The expression of P21, P27, Rb1 was upregulated in cells transfected with pre-miR-203, while downregulated in cells transfected with miR-203 inhibitor (Fig. 2D and E). Flow cytometry assay showed that proportion of cells was increased at G1 phase and decreased at the $\mathrm{S}$ and G2/M phase in MDA-MB-231 cells transfected with pre-miR-203 (Fig. 2F). Whereas, the proportion of cells was decreased at G1 phase and increased at the $\mathrm{S}$ and G2/M phase in MDA-MB-231 cells transfected with miR-203 inhibitor (Fig. 2F).

miR-203 inhibitor rescues the effects of sevoflurane in breast cancer cells. In order to determine whether miR-203 actually mediated the function of sevoflurane, we performed the rescue experiment (Fig. 3). Results indicated that miR-203 inhibitor significantly attenuated the proliferation repression caused by sevoflurane treatment in both MDA-MB-231 (Fig. 3A and C) and MCF-7 cells (Fig. 3B). miR-203 inhibitor also resisted the effect of sevoflurane on the expression of cell cycle-related genes in MDA-MB-231 cells (Fig. 3D). Flow cytometry assay showed that, compared with MDA-MB-231 cells treated with sevoflurane, the increase of cells at G1 phase and the decrease of cells at the $\mathrm{S}$ and $\mathrm{G} 2 / \mathrm{M}$ phase can be reversed by miR-203 inhibitor in MDA-MB-231 cells (Fig. 3E). 


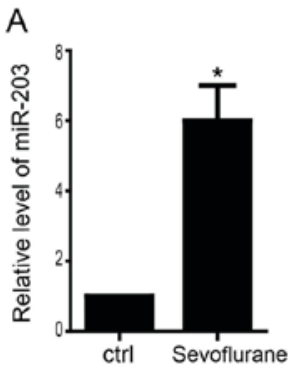

D

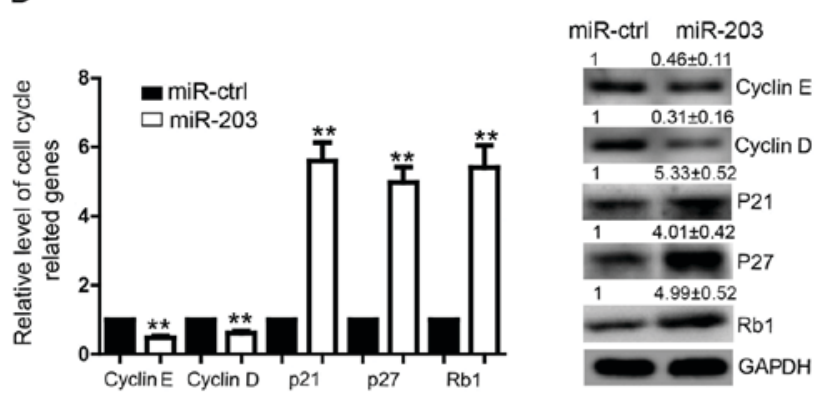

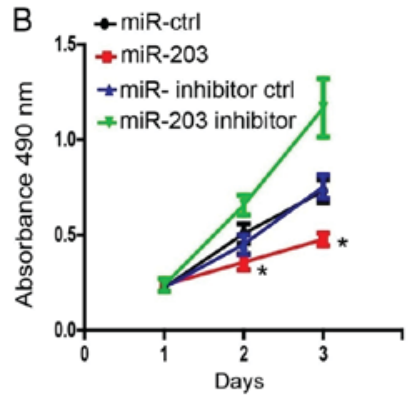

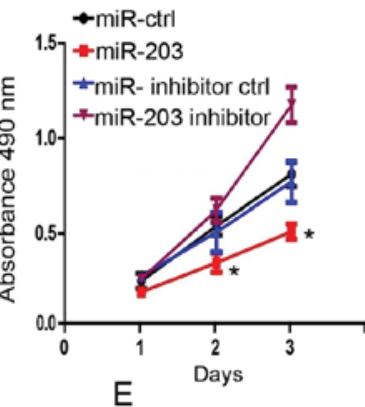

E

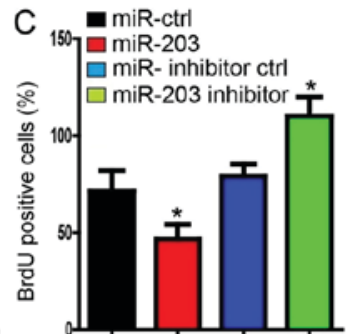

miR- $\quad$ miR-203 inhibitor ctrl inhibitor

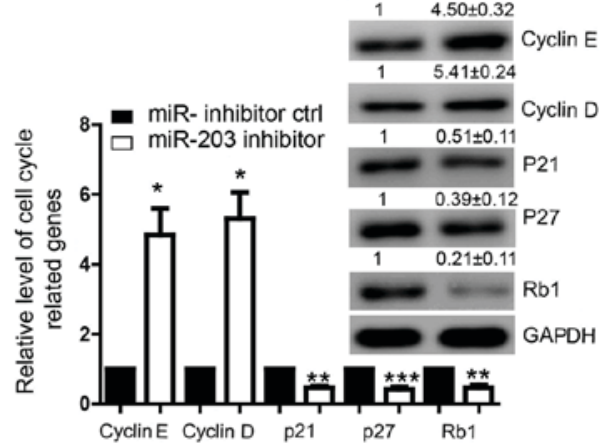

$\mathrm{F}$

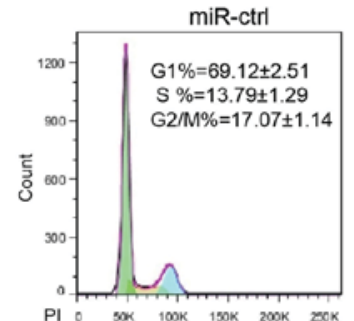

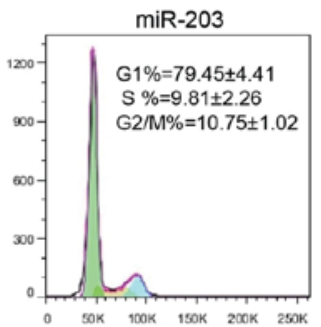
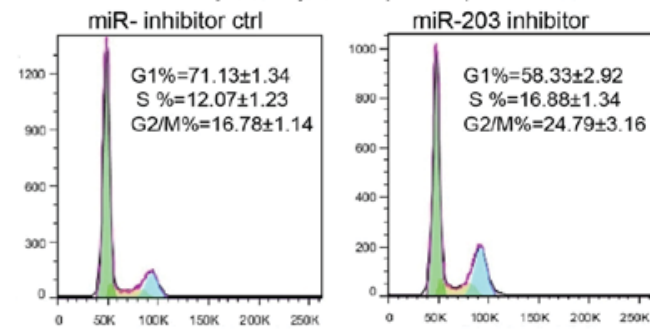

Figure 2. miR-203 was upregulated by sevoflurane and repressed the proliferation of breast cancer cells. (A) RT-qPCR showed the level of miR-203 was upregulated after sevoflurane treatment in MDA-MB-231 cells. (B) MTS assay showed the capacity of proliferation of MDA-MB-231 cells (left panel) and MCF-7 cells (right panel) transfected with miR-203 or miR-203 inhibitor. miR-203 means the pre-miR-203 mimics. miR-ctrl means the pre-miRNA control. (C) BrdU incorporation assay showed the effect of miR-203 in MDA-MB-231 cells. (D) RT-qPCR showed expression of cell cycle-related genes in MDA-MB-231 cells transfected with pre-miR-203 or pre-miRNA control. (E) Expression of cell cycle-related genes in MDA-MB-231 cells transfected with miR-203 inhibitor or control. (F) Flow cytometry assay showed the cell cycle change caused by transfection of pre-miR-203 or miR-203 inhibitor in MDA-MB-231 cells. "P<0.05, ${ }^{* *} \mathrm{P}<0.01,{ }^{* * * *} \mathrm{P}<0.001$ vs. the corresponding control.

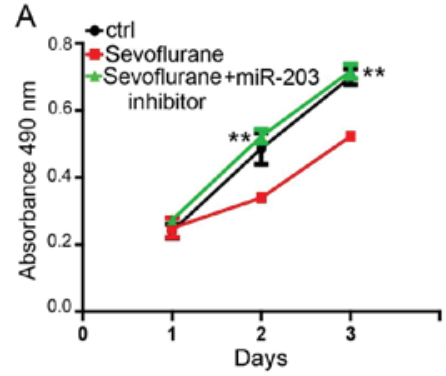

C

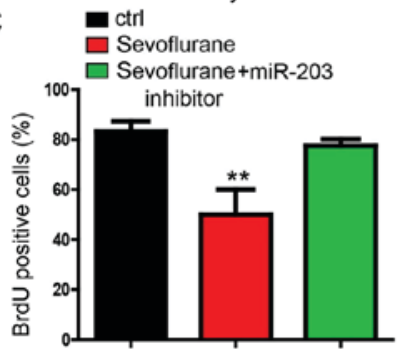

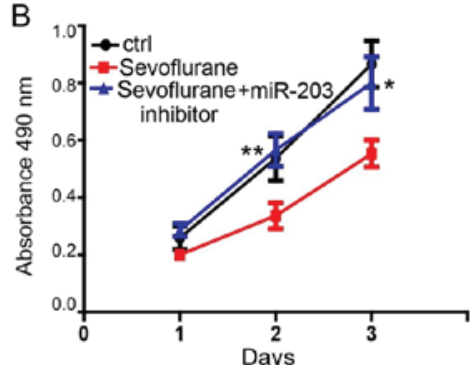

E

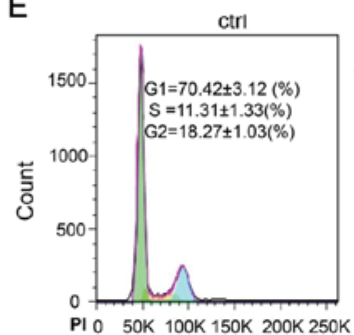

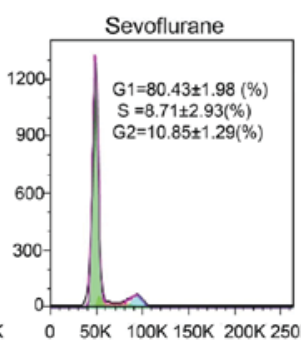
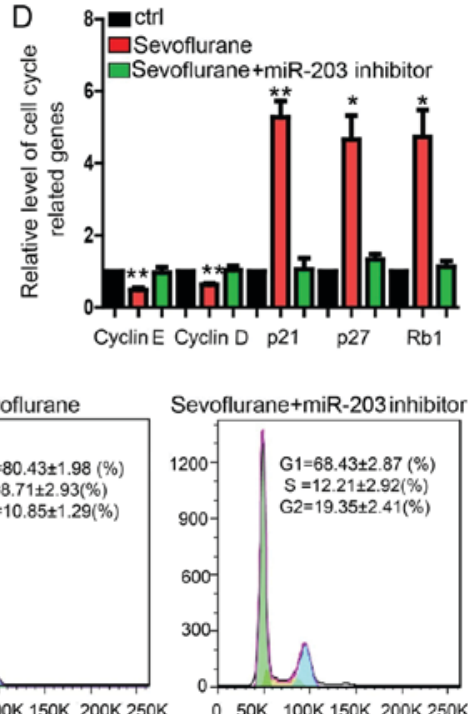

Figure 3. miR-203 inhibitor rescued the effects of sevofluranein MDA-MB-231 cells. (A) MTS assay showed that miR-203 inhibitor blocked the proliferation of MDA-MB-231 cells. (B) MTS assay showed MCF-7 cell proliferation repression caused by sevoflurane. (C) BrdU incorporation assay in the rescue experiment showed inhibition of miR-203 blocked the effects of sevoflurane in MDA-MB-231 cells. (D) Expression of cell cycle-related genes was detected by RT-qPCR in rescue experiment. (E) Flow cytometry assay showed that miR-203 inhibitor rescued the effects of sevoflurane in MDA-MB-231 cells. Data are shown as means $\pm \mathrm{SD}(\mathrm{n}=3-5) .{ }^{*} \mathrm{P}<0.05,{ }^{* *} \mathrm{P}<0.01$, vs. the corresponding control. For control group, cells were treated without sevoflurane and co-tranfected with miRNA inhibitor control RNA. The sevoflurane group means cells treated with sevoflurane and co-tranfected with miRNA inhibitor control RNA. 


\section{Discussion}

Breast cancer is the world's first serious malignant neoplasm which threaten the health of female, it had exceeded the cervical cancer and became the first factor of cancer deaths in women. Proliferation, invasion and metastasis are the important characteristic of breast cancer. Disclosing the underlying mechanism of breast cancer development will be helpful to find potential therapeutic approaches to treat breast cancer. Although sevoflurane is commonly used as an inhalational anesthetic during the surgery of cancer patients, evidences have demonstrated its effects on cell growth. A previous study reported that volatile anaesthetics, such as isoflurane, sevoflurane or desflurane, enhanced the metastasis-related cellular signaling including CXCR2 in ovarian cancer cells (24). Sevoflurane could induce the apoptosis of lung alveolar epithelial cells (25). Sevoflurane also was reported to regulate the expression of cyclin D1, but not p27Kip1 in the hippocampus (26). These studies suggested the complicated effects of sevoflurane on regulating the proliferation and cell cycle. It is significative to investigate the mechanism of regulatory effect of sevoflurane on different cells. In our study, we found that sevoflurane could significantly suppress the proliferation of MDA-MB-231 and MCF-7 breast cancer cells. Cells treated with sevoflurane arrested at the G1 phase. Our results showed that sevoflurane could be a potential therapeutic agent to prevent or treat breast cancer by regulating the cell cycle. Some other studies showed that sevoflurane possessed the opposite function, which suggested the complex effects of the sevoflurane on different cancer cells.

Among tumor-related miRNAs, miR-203 is one of the critical miRNAs that plays important roles in regulating proliferation of several types of cells. miR-203 reduced the PDGF-stimulated proliferation in human airway smooth muscle (HASM) cells (27), and formed the JNK-miR-203-p63 signaling to regulate keratinocyte proliferation and differentiation (28). miR-203 also plays important roles in cancerigenesis. miR-203 has been reported to be the tumor suppressor in osteosarcoma (29). miR-203 also directly targeted oncogene ADAM9 and long non-coding RNA HULC to inhibit the hepatocellular carcinoma cell proliferation and metastasis (30). In this study, we found that overexpression of miR-203 could suppress the proliferation and inhibition of miR-203 promoted the proliferation of MDA-MB-231 and MCF-7 breast cancer cells. Notably, miR-203 could be upregulated by sevoflurane treatment in breast cancer cells. The miR-203 inhibitor blocked the repression the proliferation of sevoflurane in breast cancer cells.

In this study, we uncovered the function of sevoflurane in regulating the breast cancer proliferation. Abnormal cell proliferation is most associated with influence of cell cycle regulation (31). The cell cycle was arrested at G1 phase, which is indicated by change of some important cell cycle-related genes expression.

It is the first time to determine the function and mechanism of sevoflurane in breast cancer cells. miR-203 is the downstream target of sevoflurane to mediate the proliferation and cell cycle. We will further study whether there are transcription factors involved in the expression of miR-203 regulated by sevoflurane. Additionally, we will also investigate the target genes of miR-203, which regulates cell cycle. We will also need further study about more similar types of breast cancers to validate the present results to confirm the mechanism of the miR-203 mediated the function of sevoflurane. Additionally, in vitro and in vivo studies will be conducted in order to validate the current results. In summary, we demonstrated a new functional role of sevoflurane/miR-203 signaling pathway on suppressing breast cancer cell proliferation and further confirmed the influence of cell cycle regulation of G1 phase and cell cycle-related genes expression.

\section{Acknowledgements}

Not applicable.

\section{Funding}

This research was supported by the Science and Technology Research Project of Henan Province (grant no. 142102310459), the Science and Technology Research Project of Henan Province (grant no. 162102310228) and the Medical Co construction Project of the Department of Health and Henan Province (grant no. 201701035).

\section{Availability of data and materials}

The datasets used and/or analyzed during the current study are available from the corresponding author on reasonable request.

\section{Authors' contributions}

JYL and LY contributed to the study idea, analyzed the majority of the data, and wrote the initial draft of the paper. $\mathrm{XG}$ performed cell cycle analysis, GJ performed the cell culture and some of the BrdU experiments, QW was involved in the experimental operation of sevoflurane-treated cells and DL treated cells with sevoflurane. JLL performed the transfection experiments, QC designed the RT-qPCR primers and performed some of the RT-qPCR experiments, QS is one of the chief directors of this study and performed most of the statistical analysis and BL designed and guided the majority of the experiments and gave final approval of the manuscript. All authors discussed the results and contributed to the writing and revisions.

\section{Ethics approval and consent to participate}

Not applicable.

\section{Consent for publication}

Not applicable.

\section{Competing interests}

The authors declare that they have no competing interests. 


\section{References}

1. Adams JM and Cory S: The Bcl-2 protein family: Arbiters of cell survival. Science 281: 1322-1326, 1998

2. Yi W, Li D, Guo Y, Zhang Y, Huang B and Li X: Sevoflurane inhibits the migration and invasion of glioma cells by upregulating microRNA-637. Int J Mol Med 38: 1857-1863, 2016.

3. Hurmath FK, Mittal M, Ramaswamy P, Umamaheswara Rao GS and Dalavaikodihalli Nanjaiah N: Sevoflurane and thiopental preconditioning attenuates the migration and activity of MMP-2 in U87MG glioma cells. Neurochem Int 94: 32-38, 2016.

4. Liang H, Yang CX, Zhang B, Wang HB, Liu HZ, Lai XH Liao MJ and Zhang T: Sevoflurane suppresses hypoxia-induced growth and metastasis of lung cancer cells via inhibiting hypoxiainducible factor-1 $\alpha$. J Anesth 29: 821-830, 2015.

5. Sugimoto H, Kawaraguchi Y, Nomura Y, Nishiwada T, Uemura K, Furuya $\mathrm{H}$ and Kawaguchi M: Exposure to $1 \%$ sevoflurane for 6 hours enhances proliferation of human colon cancer cells. Masui 64: 357-361, 2015 (In Japanese).

6. Bartel DP: MicroRNAs: Genomics, biogenesis, mechanism, and function. Cell 116: 281-297, 2004.

7. Liu Q, Wang G, Chen Y, Li G, Yang D and Kang J: A miR-590/Acvr2a/Rad51b axis regulates DNA damage repair during mESC proliferation. Stem Cell Reports 3: 1103-1117, 2014.

8. Xu N, Papagiannakopoulos T, Pan G, Thomson JA and Kosik KS: MicroRNA-145 regulates OCT4, SOX2, and KLF4 and represses pluripotency in human embryonic stem cells. Cell 137: 647-658, 2009.

9. Ivey KN, Muth A, Arnold J, King FW, Yeh RF, Fish JE, Hsiao EC, Schwartz RJ, Conklin BR, Bernstein HS and Srivastava D: MicroRNA regulation of cell lineages in mouse and human embryonic stem cells. Cell Stem Cell 2: 219-229, 2008.

10. Singaravelu R, O'Hara S, Jones DM, Chen R, Taylor NG Srinivasan P, Quan C, Roy DG, Steenbergen RH, Kumar A, et al: MicroRNAs regulate the immunometabolic response to viral infection in the liver. Nat Chem Biol 11: 988-993, 2015.

11. Shukla GC, Singh J and Barik S: MicroRNAs: Processing, maturation, target recognition and regulatory functions. Mol Cell Pharmacol 3: 83-92, 2011.

12. Laios A, O'Toole S, Flavin R, Martin C, Kelly L, Ring M, Finn SP Barrett C, Loda M, Gleeson N, et al: Potential role of miR-9 and miR-223 in recurrent ovarian cancer. Mol Cancer 7: 35, 2008.

13. Georges SA, Biery MC, Kim SY, Schelter JM, Guo J, Chang AN Jackson AL, Carleton MO, Linsley PS, Cleary MA, et al: Coordinated regulation of cell cycle transcripts by p53-inducible microRNAs, miR-192 and miR-215. Cancer Res 68: 10105-10112, 2008.

14. Wang D, Fan Z, Liu F and Zuo J: Hsa-miR-21 and Hsa-miR-29 in tissue as potential diagnostic and prognostic biomarkers for gastric cancer. Cell Physiol Biochem 37: 1454-1462, 2015.

15. Braconi C, Kogure T, Valeri N, Huang N, Nuovo G, Costinean S, Negrini M, Miotto E, Croce CM and Patel T: microRNA-29 can regulate expression of the long non-coding RNA gene $M E G 3$ in hepatocellular cancer. Oncogene 30: 4750-4756, 2011.

16. Zhang GJ, Li JS, Zhou H, Xiao HX, Li Y and Zhou T: MicroRNA-106b promotes colorectal cancer cell migration and invasion by directly targeting DLC1. J Exp Clin Cancer Res 34 $73,2015$.
17. Seifoleslami M, Khameneie MK, Mashayekhi F, Sedaghati F, Ziari K, Mansouri K and Safari A: Identification of microRNAs (miR-203/miR-7) as potential markers for the early detection of lymph node metastases in patients with cervical cancer, Tumour Biol: Oct 22, 2015 (Epub ahead of print).

18. Zhong X, Xiao Y, Chen C, Wei X, Hu C, Ling X and Liu X: MicroRNA-203-mediated posttranscriptional deregulation of CPEB4 contributes to colorectal cancer progression. Biochem Biophys Res Commun 466: 206-213, 2015.

19. Huang Z, Zhang L, Yi X and Yu X: Diagnostic and prognostic values of tissue hsa-miR-30c and hsa-miR-203 in prostate carcinoma. Tumour Biol 37: 4359-4365, 2016.

20. Yang Y, Hu R, Yan J, Chen Z, Lu Y, Jiang J and Jiang H: Sevoflurane inhibits the malignant potential of head and neck squamous cell carcinoma via activating the hypoxia-inducible factor-1 $\alpha$ signaling pathway in vitro. Int J Mol Med 41: 995-1002, 2018.

21. Nishiwada T, Kawaraguchi Y, Uemura K, Sugimoto H and Kawaguchi M: Effect of sevoflurane on human hepatocellular carcinoma HepG2 cells under conditions of high glucose and insulin. J Anesth 29: 805-808, 2015.

22. Zhang X, Zhang Y, Fan C, Wang L, Liu Y, Li A, Jiang G, Zhou H, Cai L and Miao Y: Noxin promotes proliferation of breast cancer cells via P38-ATF2 signaling pathway. Tumour Biol 39: $1010428317705515,2017$.

23. Zhang Z, Zhang B, Li W, Fu L, Fu L, Zhu Z and Dong JT: Epigenetic silencing of miR-203 upregulates SNAI2 and contributes to the invasiveness of malignant breast cancer cells. Genes Cancer 2: 782-791, 2011.

24. Iwasaki M, Zhao H, Jaffer T, Unwith S, Benzonana L, Lian Q, Sakamoto A and Ma D: Volatile anaesthetics enhance the metastasis related cellular signalling including CXCR2 of ovarian cancer cells. Oncotarget 7: 26042-26056, 2016.

25. Wei GH, Zhang J, Liao DQ, Li Z, Yang J, Luo NF and Gu Y: The common anesthetic, sevoflurane, induces apoptosis in A549 lung alveolar epithelial cells. Mol Med Rep 9: 197-203, 2014

26. Fang F, Lin W, Ling X, Song R, Liu Q, Lai B and Cang J: The hippocampal cyclin D1 expression is involved in postoperative cognitive dysfunction after sevoflurane exposure in aged mice. Life Sci 160: 34-40, 2016

27. Liao G, Panettieri RA and Tang DD: MicroRNA-203 negatively regulates c-Abl, ERK 1/2 phosphorylation, and proliferation in smooth muscle cells. Physiol Rep 3: pii: e12541, 2015.

28. Chen HL, Chiang PC, Lo CH, Lo YH, Hsu DK, Chen HY and Liu FT: Galectin-7 regulates keratinocyte proliferation and differentiation through JNK-miR-203-p63 signaling. J Invest Dermatol 136: 182-191, 2016.

29. Yang D, Liu G and Wang K: miR-203 acts as a tumor suppressor gene in osteosarcoma by regulating RAB22A, PLoS One 10: e0132225, 2015.

30. Wan D, Shen S, Fu S, Preston B, Brandon C, He S, Shen C, Wu J, Wang S, Xie W, et al: miR-203 suppresses the proliferation and metastasis of hepatocellular carcinoma by targeting oncogene ADAM9 and oncogenic long non-coding RNA HULC. Anticancer Agents Med Chem 16: 414-423, 2016.

31. Gérard C and Goldbeter A: The balance between cell cycle arrest and cell proliferation: Control by the extracellular matrix and by contact inhibition. Interface Focus 4: 20130075, 2014 